\title{
BMJ Open Do healthier foods and diet patterns cost more than less healthy options? A systematic review and meta-analysis
}

\author{
Mayuree Rao, ${ }^{1,2}$ Ashkan Afshin, ${ }^{2}$ Gitanjali Singh, ${ }^{3}$ Dariush Mozaffarian ${ }^{2,3,4}$
}

To cite: Rao M, Afshin A, Singh G, et al. Do healthier foods and diet patterns cost more than less healthy options? A systematic review and meta-analysis. BMJ Open 2013;3:e004277.

doi:10.1136/bmjopen-2013004277

- Prepublication history and additional material for this paper is available online. To view these files please visit the journal online (http://dx.doi.org/10.1136/ bmjopen-2013-004277)

Received 17 October 2013 Accepted 24 October 2013

CrossMark

For numbered affiliations see end of article.

Correspondence to Mayuree Rao;

mayuree_rao@brown.edu

\section{ABSTRACT}

Objective: To conduct a systematic review and metaanalysis of prices of healthier versus less healthy foods/diet patterns while accounting for key sources of heterogeneity.

Data sources: MEDLINE (2000-2011), supplemented with expert consultations and hand reviews of reference lists and related citations.

Design: Studies reviewed independently and in duplicate were included if reporting mean retail price of foods or diet patterns stratified by healthfulness. We extracted, in duplicate, mean prices and their uncertainties of healthier and less healthy foods/diet patterns and rated the intensity of health differences for each comparison (range 1-10). Prices were adjusted for inflation and the World Bank purchasing power parity, and standardised to the international dollar (defined as US\$1) in 2011. Using random effects models, we quantified price differences of healthier versus less healthy options for specific food types, diet patterns and units of price (serving, day and calorie). Statistical heterogeneity was quantified using $\mathrm{I}^{2}$ statistics.

Results: 27 studies from 10 countries met the inclusion criteria. Among food groups, meats/protein had largest price differences: healthier options cost $\$ 0.29 /$ serving ( $95 \% \mathrm{Cl} \$ 0.19$ to $\$ 0.40$ ) and $\$ 0.47 /$ $200 \mathrm{kcal}$ ( $\$ 0.42$ to $\$ 0.53$ ) more than less healthy options. Price differences per serving for healthier versus less healthy foods were smaller among grains (\$0.03), dairy ( $\$ 0.004)$, snacks/sweets $(\$ 0.12)$ and fats/oils (\$0.02; $p<0.05$ each) and not significant for soda/juice (\$0.11, $p=0.64)$. Comparing extremes (top vs bottom quantile) of food-based diet patterns, healthier diets cost $\$ 1.48 /$ day ( $\$ 1.01$ to $\$ 1.95$ ) and $\$ 1.54 / 2000 \mathrm{kcal}$ ( $\$ 1.15$ to $\$ 1.94$ ) more. Comparing nutrient-based patterns, price per day was not significantly different (top vs bottom quantile: $\$ 0.04 ; p=0.916$ ), whereas price per $2000 \mathrm{kcal}$ was $\$ 1.56$ ( $\$ 0.61$ to $\$ 2.51$ ) more. Adjustment for intensity of differences in healthfulness yielded similar results.

Conclusions: This meta-analysis provides the best evidence until today of price differences of healthier vs less healthy foods/diet patterns, highlighting the challenges and opportunities for reducing financial barriers to healthy eating.

\section{Strengths and limitations of this study}

- This systematic review and meta-analysis represents, to our knowledge, the most comprehensive examination of the evidence on prices of more versus less healthy foods and diet patterns. The strengths include the systematic search; adjustment for inflation and purchasing power parity; separate analyses of food groups, diet patterns and units of price; and evaluation of heterogeneity by food type, intensity of contrast and unit of comparison.

- The study was limited by less available data on restaurant prices and prices from low-income and middle-income countries. High statistical heterogeneity was evident, although the actual observed range of price differences was more modest.

\section{INTRODUCTION}

Consumption of a healthy diet is a priority for reducing chronic diseases including obesity, diabetes, cardiovascular diseases and several cancers. This is especially crucial for socioeconomically disadvantaged populations, who have less healthy diets and higher disease risk than higher socioeconomic groups. ${ }^{1-4}$ Many factors, including the availability and cultural acceptability of healthy foods, pose obstacles to the promotion of healthy diets. One of the most commonly described barriers is cost: conventional wisdom holds that healthier foods and diets are more expensive than less healthy options, an assumption which has become "a reflexive part of how we explain why so many Americans are overweight."

Yet, while several studies have evaluated whether healthier foods or diets cost more, ${ }^{6-10}$ the evidence has never, to our knowledge, been systematically reviewed nor quantified to critically evaluate all the evidence for the relationship between healthfulness of foods or diet patterns and price. In addition, little is known about the potential heterogeneity of this relationship. For example, price differences may vary by the foods or diets being 
compared. Many studies compare healthier and less healthy versions of the same food (ie, more vs less healthy grains), while other studies examine the price differences of healthier vs less healthy overall diet patterns, containing very different foods. Price differences may also depend on how healthfulness is defined, ranging from definitions based on single nutrients (eg, fat or sugar content) to those based on food types or more complex diet patterns. The intensity of the health contrast could also affect the price difference; for example, a fast food meal versus a healthier home-cooked meal is a more extreme comparison than a low-fat versus high-fat cookie. Finally, price differences may vary by the unit of comparison, for example, per serving, per calorie, or per day. In particular, price differences per calorie may be limited by reverse causation, as healthier foods (eg, fruits and vegetables) often have fewer calories; and evaluation of price differences per serving may alter the conclusions. ${ }^{11}$

To address each of these key gaps in knowledge, we performed a systematic review and meta-analysis of the evidence for relationships between the healthfulness of foods/diet patterns and their price, including consideration of different food groups and diet patterns, definitions of healthfulness, intensities of the contrast and units of comparison (calorie, serving and daily diet).

\section{METHODS}

We followed the Meta-analysis of Observational Studies in Epidemiology (MOOSE) guidelines throughout all stages of design, implementation and reporting. ${ }^{12}$ The independent and dependent variables of interest were the healthfulness of foods or diet patterns and their price, respectively. The protocol, which was not altered after beginning the study, is available from the authors on request.

\section{Search strategy and selection of articles}

Systematic searches were conducted using MEDLINE (via PubMed) for all eligible English language articles published through December 2011. Additional articles were identified by expert consultations, and hand-reviews of reference lists and the first 20 "Related citations" in PubMed for all studies included after full-text review. Because our focus was on contemporary price differences related to healthfulness, and because such price differences could vary in earlier decades, we focused our search on studies having collected price data in the year 2000 or later. The search query combined the terms related to foods/diet patterns, price, setting and time (supporting appendix 1).

Studies were included if they reported the mean retail prices of foods (including beverages) or diet patterns stratified by a specified measure of healthfulness, as well as sufficient (or obtainable by direct contact) data to derive or estimate the statistical uncertainty (ie, SE of difference in means). No foods or diet patterns were excluded. Studies reporting wholesale price or perceived rather than the actual price, as well as reviews, letters, editorials and commentaries, were excluded.
One investigator screened all identified studies based on these inclusion and exclusion criteria by title and abstract. Following screening, remaining full-text articles were obtained and reviewed independently and in duplicate by two investigators for final inclusion/exclusion using the same criteria. Any differences were resolved by discussion among all of the investigators. A list of excluded citations is available from the authors on request.

\section{Data extraction and synthesis}

For each included study, two investigators extracted data independently and in duplicate using a standardised electronic spreadsheet. Data extracted included first author, title, publication year, year of price data collection, source of price data, demographic variables of study participants and/or community from which price data were collected, definition(s) of healthfulness, food/diet pattern comparison(s), the number of participants and/or the number of foods and mean prices and uncertainties (including unit, eg, calorie and serving) of the healthier and less healthy foods/diet patterns compared. Because the magnitude of differences in healthfulness could influence price differences, we also rated the intensity of the contrast in health difference between the compared foods/diet patterns on an ordinal scale (1-10), with 1 representing a very small difference in healthfulness and 10 a marked difference in healthfulness. These ratings were based on growing evidence that different types of foods and food-based diet patterns predict chronic disease outcomes better than differences in single nutrients. ${ }^{13}$ Thus, foods/diet patterns that differed by a single nutrient were rated as lower intensity, while foods/diet patterns that differed across multiple aspects (eg, three home-cooked meals vs three fast-food meals) were rated as higher intensity. The intensity of contrast was rated independently and in duplicate by two investigators with good concordance (generally $\leq 2$ points); discrepancies were resolved by group discussion. These ratings are available in the supporting information.

\section{Statistical analysis}

Our primary endpoint was the difference in mean price between the healthier and less healthy foods or diet patterns. When data on the variance of the difference in means or information to directly calculate this variance were not reported, we calculated it based on the variance of the mean prices in each category, based on standard formulas ${ }^{14}$ :

$$
\begin{aligned}
& \mathrm{SE}_{\text {diff }}=\sqrt{\mathrm{SE}_{\text {healthier }}^{2}+\mathrm{SE}_{\text {less healthy }}^{2}} \\
& \mathrm{SE}_{\text {diff }}=\sqrt{\frac{\mathrm{SD}_{\text {healthier }}^{2}+\mathrm{SD}_{\text {less healthy }}^{2}}{\mathrm{n}_{\text {healtheir }}+\mathrm{n}_{\text {less healthy }}}}
\end{aligned}
$$

For nine studies in which mean prices were reported without their uncertainty, the SEs were imputed from the number of observations in each category, based on 
linear regression of studies with complete data, performed separately for market surveys (6 studies comparing samples of foods) and individual dietary surveys (3 studies comparing diets across samples of participants; supporting figure 1 ).

We recognised that price comparisons within food groups (ie, healthier vs less healthy options within the same category of food) may vary from price comparisons across overall diet patterns. Furthermore, price differences may vary for diet patterns largely based on foods versus diet patterns largely based on one or a few isolated nutrients. Thus, we separately investigated price differences that compared options within a single similar category of food (eg, meats/protein, grains, dairy), price differences that compared varying concordance to foodbased diet patterns (eg, Alternative Healthy Eating Index, Western or Mediterranean diet patterns) and price differences that compared varying concordance to isolated nutrient-based (eg, fat, sugar) diet patterns. For analyses of diet patterns, we evaluated price differences for the extreme categories (eg, the top vs bottom quartile or quintile) of diet, to enable comparisons of the largest differences in diet quality.

Because price differences could also vary by the unit of comparison, findings for foods were evaluated and standardised to one usual serving and to $200 \mathrm{kcal}$; and for diet patterns, standardised to 1 day (3 meals) and to $2000 \mathrm{kcal}$. Standard serving sizes were based on the 2011 United States Department of Agriculture (USDA) MyPlate guidelines or, if not available from MyPlate, on nutrition labels from a major grocery website. ${ }^{15} 16$ Calorie conversions were derived from the USDA database. ${ }^{17}$ For standardising studies of food baskets to meals, one serving of any food was assigned as onefourth of a meal, except for condiments, fats or oils for which one serving was assigned one-eighth of a meal. All price differences were adjusted for inflation by country to reflect the prices in 2011. In addition, to account for the varying values of currencies across countries, these prices were further adjusted for purchasing power parity by standardising to 2011 international dollars; one international dollar is defined as US $\$ 1$. Inflation rates and purchasing power parity conversion factors were obtained from the World Bank; 2011 is the latest year for which these data are available. ${ }^{18}$ We also repeated all analyses with an additional weighting for the intensity of the contrast in healthfulness (range 1-10), that is, with greater differences (higher intensity values) carrying greater weights.

Summary estimates were quantified using inversevariance weighted, random effects meta-analysis (metan command in Stata). Statistical heterogeneity was evaluated using the $\mathrm{I}^{2}$ statistic. Metaregression (metareg command in Stata) was performed on intensity, study location (USA/Canada vs other) and type of survey (market survey vs dietary survey) to explore the potential sources of heterogeneity. Publication bias was assessed using the Egger test and visual inspection of funnel plots. Statistical analyses were performed using Stata V.12 (StataCorp, College Station, Texas, USA), with twotailed $\alpha=0.05$.

\section{RESULTS}

\section{Search results and study characteristics}

Of 1010 articles identified by the MEDLINE search and screened for inclusion, 83 were selected for full-text review (figure 1). Of these, 19 articles met the inclusion criteria, and an additional 8 articles were identified from hand-searches of references lists, related citations in PubMed and expert consultations. Among the final 27 studies, 14 were conducted in the USA, 2 in Canada, 6 in Europe and 5 in other countries including South Africa, New Zealand, Japan and Brazil (table 1). Twelve studies were market surveys, and 15 were dietary surveys. The number of foods evaluated by the market surveys

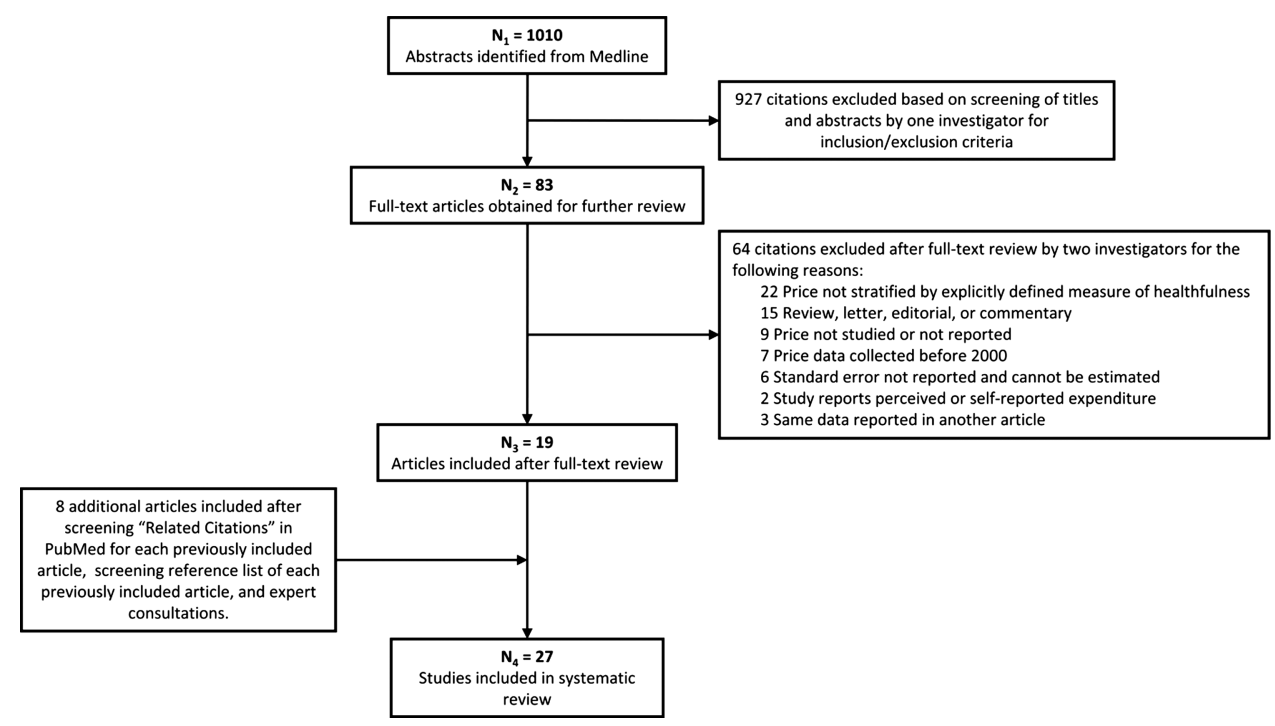

Figure 1 Search and screening of studies comparing prices of healthier and less healthy foods or diet patterns. 
ranged from 2 to 133, with prices collected from between 1 and 1230 stores. The number of participants evaluated by the dietary surveys ranged from 30 to 78 191. Several studies reported prices for multiple food comparisons or from different types of stores and contributed more than one estimate to the analysis.

\section{Price differences of foods}

Evidence on price comparisons within similar food groups was available in six major food groups, including meats/protein, grains, dairy, snacks/sweets, fats/oils and soda/juice.

Per serving, meats/protein exhibited the largest price difference by healthfulness (figure 2A). On average, the healthier choice was $\$ 0.29$ more expensive per serving than the less healthy choice $(95 \%$ CI $\$ 0.19$ to $\$ 0.40)$. Considerable statistical heterogeneity was evident $\left(\mathrm{I}^{2}=99.4 \%\right)$ that appeared at least partly related to the type of comparison. For example, price differences by healthfulness appeared largest for chicken, intermediate for beef, and smallest for peanut butter. Healthier snacks/ sweets, grains and fats/oils were also more expensive per serving than less healthy options, but with smaller price differences: for snacks/sweets, $\$ 0.12 /$ serving ( $\$ 0.02$ to $\$ 0.23$ ); for grains, $\$ 0.03 /$ serving ( $\$ 0.01$ to $\$ 0.05$ ) and for fats/oils, $\$ 0.02 /$ serving ( $\$ 0.01$ to $\$ 0.02$ ). For dairy, healthier options were slightly less expensive per serving (-\$0.004/serving; 95\% CI $-\$ 0.005$ to $-\$ 0.004)$, although pooled findings were driven by one study with reported high statistical certainty. Excluding this study, healthier dairy options were similar in price to less healthy options ( $-\$ 0.004 /$ serving, $\mathrm{p}=0.389)$. No significant price differences per serving were seen between healthier and less healthy soda/juice $(\$ 0.11 ; 95 \%$ CI $-\$ 0.34$ to $\$ 0.56$; $\mathrm{I}^{2}=25.1 \%$ ), but only two studies evaluated this comparison.

For most of these food groups, findings were similar or stronger for pooled price differences standardised per calorie (figure 2B), rather than per serving. The largest price difference was again among meats/protein, with healthier options costing $\$ 0.47 / 200 \mathrm{kcal}$ more $(\$ 0.42-\$ 0.53)$ than less healthy options. The main exception was dairy foods, for which the pooled price difference per $200 \mathrm{kcal}$ was much greater than the price difference per serving. Per $200 \mathrm{kcal}$, healthier dairy foods were $\$ 0.21$ more expensive than less healthy options (\$0.11-\$0.31), consistent with the strong calorie effect of the metric (fat content) that was used to define healthfulness in this food group.

\section{Price differences of diet patterns}

Twenty studies evaluated price differences according to concordance with overall healthful diet patterns, with 14 studies evaluating more food-based patterns and 7 studies evaluating more nutrient-based patterns (one study evaluated both ${ }^{19}$ ).

Comparing extreme categories of food-based diet patterns, the highest category of healthier diets cost $\$ 1.48$ / day (\$1.01 to $\$ 1.95)$ more than the lowest category (figure 3A). The findings were broadly consistent across several different definitions of healthful diet patterns, including based on the Mediterranean dietary pattern, Western dietary pattern, Alternative Healthy Eating Index, fruit and vegetable intake and energy density. Some food-based diet patterns exhibited smaller or no price differences, including based on the Healthy Eating Index, the Environmental Standards for Healthy Eating and comparing home-cooked to fast food meals. When standardised to $2000 \mathrm{kcal}$, healthier food-based diet patterns cost $\$ 1.54$ more than less healthy options $(\$ 1.15-$ $\$ 1.94$ ), with price differences modestly larger for patterns based on the Alternative Healthy Eating Index and energy density, smaller for patterns based on fruit and vegetable consumption alone, and no longer significant for the Mediterranean dietary pattern (figure 3B).

For diet patterns based largely on single or a few isolated nutrients, the price of the highest (healthiestrated) category of diets meeting these criteria was not significantly different from the lowest (least healthyrated) category of diets meeting the criteria when based on a day's intake (figure 4A). In contrast, when standardised to $2000 \mathrm{kcal}$, the highest category of nutrientbased patterns cost $\$ 1.56$ more than the lowest $(\$ 0.61-$ $\$ 2.51$; figure $4 \mathrm{~B}$ ). Price differences per $2000 \mathrm{kcal}$ were larger relative to the per day estimates for patterns based on fat; sugar; and fibre, fat, and sugar combined.

We also performed analyses restricted to the US studies. Results were similar: healthier food-based diet patterns cost an average of $\$ 1.49 /$ day $(\$ 0.60$ to $\$ 0.237$; $\mathrm{n}=7$ studies) and $\$ 1.79 / 2000 \mathrm{kcal}(\$ 0.78$ to $\$ 2.80 ; \mathrm{n}=6$ studies) more than less healthy patterns. Healthier nutrient-based diet patterns cost an average of $\$ 0.40 /$ day (\$0.17 to $\$ 0.63 ; \mathrm{n}=3$ studies) and $\$ 2.46 / 2000 \mathrm{kcal}(-\$ 2.17$ to $\$ 7.09$; $\mathrm{n}=2$ studies) more than less healthy patterns.

\section{Intensity of the contrast in healthfulness}

We repeated all analyses adjusting for differences in the intensity of contrast in healthfulness in each comparison. Within food groups, intensities of contrasts were generally rated in the 4-6 range, with a smallest contrast of 3 (eg, comparing different types of cookies) and a largest of 9 (eg, comparing fruits/vegetables to packaged snacks). For food groups, intensity-weighted price differences were generally similar to the unweighted findings (supporting figure 2). Contrasts of diet patterns were most often rated 6 or 7 , with a smallest contrast of 1 (comparing patterns based on total fat alone) to a largest of 10 (comparing 3 healthier home-cooked meals to 3 fast food meals). Compared with unweighted comparisons, the intensity-weighted price differences of healthier versus less healthy food-based diet patterns were similar: $\$ 1.46 /$ day ( $\$ 1.00$ to $\$ 1.92)$ and $\$ 1.53 /$ $2000 \mathrm{kcal}$ (\$1.14 to $\$ 1.93$; supporting figure 3 ). Intensity-weighted price differences were also similar to unweighted results for nutrient-based diet patterns: $\$ 0.11 /$ day ( $-\$ 0.64$ to $\$ 0.85$ ) and $\$ 1.66 / 2000 \mathrm{kcal}(\$ 0.55$ to $\$ 2.78$; supporting figure 4$)$. 
Table 1 Characteristics of food price studies included in meta-analysis

\begin{tabular}{|c|c|c|c|c|}
\hline Author, year & $\begin{array}{l}\text { Time of price data } \\
\text { collection }\end{array}$ & Participants or foods, setting & Assessment of healthfulness & Price assessment \\
\hline \multicolumn{5}{|l|}{ Market studies } \\
\hline $\begin{array}{l}\text { Cassady et al, } \\
2007^{4{ }^{*}}\end{array}$ & $\begin{array}{l}\text { June } 2003 \text {, } \\
\text { September- } \\
\text { October } 2003 \text {, } \\
\text { March-April } 2004\end{array}$ & $\begin{array}{l}35 \text { foods from } 25 \text { stores in } \\
\text { Sacramento and Los Angeles, } \\
\text { California }\end{array}$ & $\begin{array}{l}\text { Fruit and vegetable basket meeting } 2005 \\
\text { Dietary Guidelines vs } 1995 \text { Thrifty Food } \\
\text { Plan fruit and vegetable basket†‡ }\end{array}$ & $\begin{array}{l}\text { Cross-sectional price survey conducted } \\
\text { across } 3 \text { time periods in chain } \\
\text { supermarkets, small independent grocery } \\
\text { stores, and supermarkets selling bulk food } \\
\text { items with no membership fee }\end{array}$ \\
\hline $\begin{array}{l}\text { Jetter and Cassady, } \\
2006^{7}\end{array}$ & $\begin{array}{l}\text { June } 2003 \text {, } \\
\text { September } 2003 \text {, } \\
\text { March-April } 2004\end{array}$ & $\begin{array}{l}133 \text { foods from } 25 \text { stores in } \\
\text { Sacramento and Los Angeles, } \\
\text { California }\end{array}$ & $\begin{array}{l}\text { Market basket with four times the amount of } \\
\text { fibre and one-fifth the grams of total fat vs } \\
1995 \text { Thrifty Food Plan market basket§ }\end{array}$ & $\begin{array}{l}\text { Cross-sectional price survey conducted } \\
\text { across } 3 \text { time periods in chain } \\
\text { supermarkets, small independent grocery } \\
\text { stores, and supermarkets selling bulk food } \\
\text { items with no membership fee }\end{array}$ \\
\hline Katz DL et al, $2011^{42}$ & NR & $\begin{array}{l}131 \text { foods in } 8 \text { food categories from } \\
6 \text { stores in Jackson County, } \\
\text { Missouri }\end{array}$ & 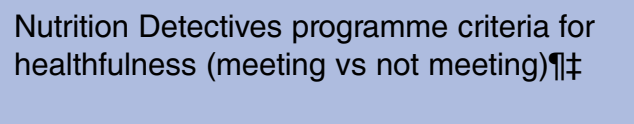 & $\begin{array}{l}\text { Prices collected from chain grocery stores } \\
\text { accessible to research assistant }\end{array}$ \\
\hline $\begin{array}{l}\text { Krukowski et al, } \\
2010^{40}\end{array}$ & $\begin{array}{l}\text { February-April } \\
2008\end{array}$ & $\begin{array}{l}20 \text { foods from } 42 \text { stores in Arkansas } \\
\text { and Vermont }\end{array}$ & $\begin{array}{l}10 \text { high-fibre, low-fat, low-sugar foods vs } 10 \\
\text { low-fibre, high-fat, high-sugar foods }{ }^{\star \star}\end{array}$ & $\begin{array}{l}\text { Overweight individuals entering a } \\
\text { behavioural weight loss research } \\
\text { programme self-reported their primary } \\
\text { grocery store. Trained data collectors } \\
\text { assessed food prices at these stores }\end{array}$ \\
\hline Liese et al, $2007^{43}$ & 2004 & $\begin{array}{l}8 \text { foods from } 75 \text { stores in } \\
\text { Orangeburg County, South Carolina }\end{array}$ & $\begin{array}{l}\text { Lean ground beef vs high-fat ground beef; } \\
\text { skinless and boneless chicken breasts vs } \\
\text { chicken drumsticks; high-fibre bread vs } \\
\text { low-fibre bread; low-fat/non-fat milk vs whole } \\
\text { milk }\end{array}$ & $\begin{array}{l}\text { All food stores in county identified from } \\
\text { Licensed Food Service Facilities Database } \\
\text { and in-person verification. Prices recorded } \\
\text { and reported by store type (supermarket, } \\
\text { grocery store, convenience store) }\end{array}$ \\
\hline Lipsky, $2009^{44}$ & 2008 & $\begin{array}{l}2 \text { food groups from } 1 \text { store in } \\
\text { mid-Atlantic region }\end{array}$ & $\begin{array}{l}\text { Produce (fruits, vegetables) vs snacks } \\
\text { (cookies, chips) }\end{array}$ & Price collected from online supermarket \\
\hline $\begin{array}{l}\text { McDermott and } \\
\text { Stephens, } 2010^{8}\end{array}$ & NR & $\begin{array}{l}34 \text { foods from } 4 \text { stores in Baltimore, } \\
\text { Maryland }\end{array}$ & $\begin{array}{l}3 \text { cups milk/dairy, } 5 \text { oz lean meat, } 1.5 \mathrm{c} \text { fruit, } \\
2.5 \text { cups vegetables, and } 6 \text { oz grains per } \\
\text { day vs breakfast, lunch, and dinner from } \\
\text { fast-food restaurant }\end{array}$ & $\begin{array}{l}\text { Prices for healthier foods obtained from } 3 \\
\text { large supermarket chains. Prices for less } \\
\text { healthy foods obtained from a large, } \\
\text { multinational fast-food chain }\end{array}$ \\
\hline Ricciuto et $a l^{45}$ & November 2002 & $\begin{array}{l}229 \text { foods from } 9 \text { stores in Toronto, } \\
\text { Canada }\end{array}$ & $\begin{array}{l}\text { Margarine with vs without label 'low in } \\
\text { saturated fat' or 'cholesterol free' }\end{array}$ & $\begin{array}{l}\text { Prices obtained from } 9 \text { stores of } 3 \text { major } \\
\text { chain supermarkets }\end{array}$ \\
\hline Ricciuto et $a f^{46}$ & $\begin{array}{l}\text { November } 2002 \\
\text { and November- } \\
\text { December } 2006\end{array}$ & $\begin{array}{l}229 \text { foods from } 9 \text { stores in } 2002 \text { and } \\
274 \text { foods from } 10 \text { stores in } 2006 \text { in } \\
\text { Toronto, Canada }\end{array}$ & $\begin{array}{l}\text { Trans fat-free vs non-trans fat-free } \\
\text { margarine } \dagger \dagger\end{array}$ & $\begin{array}{l}\text { Prices obtained from } 10 \text { stores of } 3 \text { major } \\
\text { chain supermarkets }\end{array}$ \\
\hline Temple and Steyn ${ }^{39}$ & May 2006 & $\begin{array}{l}24 \text { foods from } 1 \text { store in each of } 3 \\
\text { communities in Cape Town, South } \\
\text { Africa }\end{array}$ & $\begin{array}{l}\text { Higher-fibre, lower-fat, and lower-sugar daily } \\
\text { menu vs typical daily menuł‡ }\end{array}$ & $\begin{array}{l}\text { Food prices obtained from supermarkets; } \\
\text { price reported by community }\end{array}$ \\
\hline
\end{tabular}


Table 1 Continued

Time of price data

collection

Participants or foods, setting

Author, year

June-August 200514 foods from 1230 stores in Waikato and Lakes Districts, New Zealand

Wilson and Mansoor, January 23, 2005 $2005^{48}$ New Zealand

Dietary studies

Aggarwal et al, $2011^{38}$

April-June 20041266 participants in Seattle Obesity and May-July 2006 Study; 3 stores

Bernstein et al, $2010^{6} 2001-2002$

78191 participants in Nurses Health Study; 467 foods

\section{Drewnowski et al, NR}

$2004^{19}$

Lopez et al, $2009^{49}$ May 2005

Drewnowski, $2009^{50}$

Monsivais et al $2012^{51}$

837 participants in Val-de-Marne, France; 57 foods

11195 participants in Spain; 136 foods

164 participants; 384 foods from 3 stores in Seattle, Washington

April-June 20041295 participants; 384 foods from and May-July 20063 stores in Seattle, Washington

\section{Assessment of healthfulness}

\section{Price assessment}

Basket including bread, chicken, beef/pork, Prices obtained from 1230 stores sugar-sweetened drinks, milk, snacks, (including supermarkets, dairies, bakeries, spreads, and sugar meeting vs not meeting service stations, restaurants and

New Zealand food-based dietary guidelines takeaways). Each food was not available in (ie, less energy-dense; lower-fat, salt and every store sugar; and higher-fibre) $\ddagger$

Basket of foods including butter, butter/ Within each of 9 food-types, items with vegetable oil blend, margarine type spread, highest and lowest levels of saturated fat cream cheese, hard cheese, grated cheese, identified and prices obtained from 2 large cream, biscuits \& crackers and chocolate with mean saturated fat of $14.9 \mathrm{~g} / 100 \mathrm{~g}$ vs basket of same foods with mean saturated fat of $29.0 \mathrm{~g} / 100 \mathrm{~g} \ddagger \S \S$

Dietary energy density, $\mathrm{kJ} / \mathrm{g}$ and mean adequacy ratio (quintile 1 vs quintile 5 ) $\uparrow \uparrow$

Alternative Healthy Eating Index score (quintile 5 vs quintile 1 ) supermarkets

Fats and sweets intake, fruit and vegetable intake, total fat intake, and sucrose intake (quintile 1 vs quintile 5)

Western dietary pattern score and

Mediterranean dietan 1 vs quintile 5$) \dagger \dagger \dagger$

Dietary energy density, $\mathrm{kcal} / \mathrm{g}$ (tertile 1 vs tertile 3) FFQ component foods. Food prices obtained from 3 supermarket chains via in-store visits and websites

Diet cost calculated by merging FFQ database with USDA Center for Nutrition Policy and Promotion price database Diet cost calculated from food prices from French National Institute of Statistics

Diet cost calculated from food prices from Ministry of Industry, Tourism and Commerce of Spain. When data not available from ministry, food prices obtained from national supermarket websites

Diet cost calculated based on prices of FFQ component foods. Prices obtained at supermarket chains. Price reported separately for men and women

Nutrient density of diet (quintile 5 vs quintile Diet cost calculated based on prices of 1 of diet cost) $\ddagger \ddagger \ddagger \S \S \S$ FFQ component foods. Food prices obtained from 3 supermarket chains via in-store visits and websites 


\begin{tabular}{|c|c|c|c|c|}
\hline Author, year & $\begin{array}{l}\text { Time of price data } \\
\text { collection }\end{array}$ & Participants or foods, setting & Assessment of healthfulness & Price assessment \\
\hline $\begin{array}{l}\text { Mozaffarian et al, } \\
2012^{37}\end{array}$ & 2003-2004 & $\begin{array}{l}1294 \text { snack-days in } 32 \text { YMCA } \\
\text { after-school programmes in } 4 \\
\text { metropolitan areas }\end{array}$ & $\begin{array}{l}\text { Environmental Standards for Healthy Eating } \\
\text { (meeting vs not meeting)ๆा }\end{array}$ & $\begin{array}{l}\text { Prices from USDA Center for Nutrition } \\
\text { Policy and Promotion price database }\end{array}$ \\
\hline $\begin{array}{l}\text { Murakami et al, } \\
2009^{52}\end{array}$ & 2004 & $\begin{array}{l}596 \text { pregnant women in Neyagawa } \\
\text { City, Osaka Prefecture, Japan; } 150 \\
\text { foods }\end{array}$ & 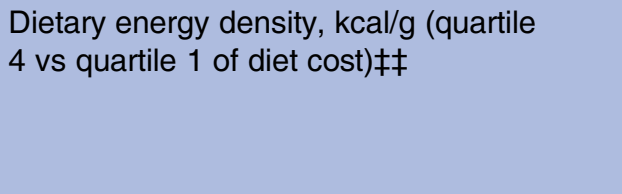 & $\begin{array}{l}\text { Diet cost based on National Retail Price } \\
\text { Survey. For foods not in survey, prices } \\
\text { obtained from websites of nationally } \\
\text { distributed supermarket or fast-food } \\
\text { restaurant chains }\end{array}$ \\
\hline $\begin{array}{l}\text { Rauber and Vitolo, } \\
2009^{53}\end{array}$ & NR & $\begin{array}{l}346 \text { children aged } 3-4 \text { years; } 3 \\
\text { brands each of } 104 \text { foods from } 2 \\
\text { stores in São Leopoldo, Brazil }\end{array}$ & $\begin{array}{l}\text { Calories from sugar-rich foods ( } \leq 150 \text { vs } \\
>150 \text { kcal) and calories from fat-rich foods } \\
(\leq 150 \text { vs }>150 \text { kcal) }\end{array}$ & $\begin{array}{l}\text { Diet cost based on prices obtained at a } \\
\text { large establishment (supermarket or } \\
\text { hypermarket) and a small establishment } \\
\text { (market, minimart or bakery) }\end{array}$ \\
\hline Rehm et al, $2011^{9}$ & 2001-2002 & 4744 participants in NHANES & $\begin{array}{l}\text { Healthy Eating Index-2005 score (quintile } \\
5 \text { vs quintile } 1 \text { of diet cost) } \neq \ddagger \ddagger\end{array}$ & $\begin{array}{l}\text { Diet cost calculated from USDA Center for } \\
\text { Nutrition Policy and Promotion price } \\
\text { database }\end{array}$ \\
\hline Rydén et al, $2008^{54}$ & Autumn 2005 & $\begin{array}{l}30 \text { participants in Kalmar province, } \\
\text { Sweden; } 600 \text { foods }\end{array}$ & Mediterranean diet vs typical diet†††† & $\begin{array}{l}\text { Diet cost calculated from prices from } \\
\text { Statistics Sweden. For foods not reported } \\
\text { by Statistics Sweden, prices obtained from } \\
4 \text { stores and } 2 \text { online stores }\end{array}$ \\
\hline $\begin{array}{l}\text { Rydén and Hagfors, } \\
2011^{10}\end{array}$ & Spring 2010 & $\begin{array}{l}2160 \text { children ages } 4,8 \text {, and } 11 \text { y in } \\
\text { Sweden; prices of } 991 \text { foods from } \\
\text { Statistics Sweden, and stores when } \\
\text { not available from Statistics Sweden }\end{array}$ & $\begin{array}{l}\text { Healthy Eating Index-2005 score } \\
(>70 \text { vs }<50)^{\star \star \star \star}\end{array}$ & $\begin{array}{l}\text { Average national prices of } 391 \text { foods } \\
\text { obtained from Statistics Sweden. Prices of } \\
\text { remaining } 600 \text { foods were not available } \\
\text { from Statistics Sweden; obtained from one } \\
\text { online supermarket and one online grocery } \\
\text { store }\end{array}$ \\
\hline $\begin{array}{l}\text { Schroder et al, } \\
2006^{55}\end{array}$ & May 2005 & $\begin{array}{l}2847 \text { participants in Girona, Spain; } \\
165 \text { foods }\end{array}$ & 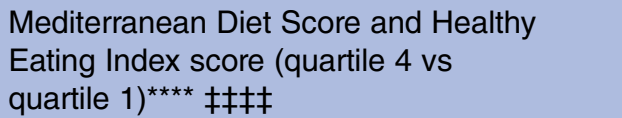 & $\begin{array}{l}\text { Diet cost calculated from average national } \\
\text { price database of the Secretaria de Estado } \\
\text { de Turismo y Comercio de Espana }\end{array}$ \\
\hline $\begin{array}{l}\text { Townsend et al, } \\
2009^{56}\end{array}$ & 2006 & $\begin{array}{l}112 \text { participants; } 8 \text { stores in San } \\
\text { Joaquin, Solano, Calavaras, and } \\
\text { Tulare counties in California }\end{array}$ & $\begin{array}{l}\text { Dietary energy density, kcal/g (tertiles } \\
1 \text { vs 3) }\end{array}$ & $\begin{array}{l}\text { Diet cost (with and without beverages) } \\
\text { calculated based on prices of FFQ } \\
\text { component foods. Prices obtained from a } \\
\text { large supermarket chain store and a small } \\
\text { independent market in each county }\end{array}$ \\
\hline
\end{tabular}


Table 1 Continued

\begin{tabular}{|c|c|c|c|c|}
\hline Author, year & $\begin{array}{l}\text { Time of price data } \\
\text { collection }\end{array}$ & Participants or foods, setting & Assessment of healthfulness & Price assessment \\
\hline
\end{tabular}

${ }^{*}$ This study is not included in analysis since it is the only market survey on fruits and vegetables.

†Baskets include varying amounts of fruits, dark green vegetables, orange vegetables, legumes, starchy vegetables, and 'other' vegetables.

$\neq$ Components of baskets also compared.

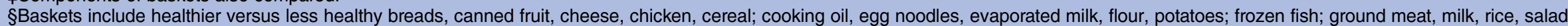
dressing, spaghetti, margarine and tuna fish. Baskets also include fresh fruits and vegetables, eggs, and beans which are unchanged between two baskets.

INutrition detectives criteria: subjectively determined to not have excessive marketing-related claims or images on the front of the package; not have an unhealthy ingredient such as sugar or white flour listed first on ingredient list, does not contain partially hydrogenated oil or high-fructose corn syrup, and does not have a long ingredient list relative to other items in the same food category. For grain-based products only, more nutritious foods also contain at least $2 \mathrm{~g}$ fibre per serving.

${ }^{* *}$ Baskets include healthy versus less healthy juice, hot dogs, ground beef, chips, bread, soda, milk, frozen dinner, baked goods and cereals.

t†Trans fat-free defined as containing (1) $\leq 0.2 \mathrm{~g}$ TFA per $10 \mathrm{~g}$; (2) $\leq 2 \mathrm{~g}$ TFA and SFA combined per $10 \mathrm{~g}$; and (3) $\leq 15 \%$ energy from TFA and SFA combined per $10 \mathrm{~g}$

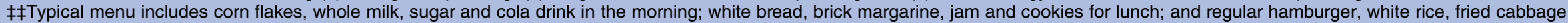
and candied butternut for dinner. Healthier menu includes bran flakes, skim milk, banana and orange juice in the morning, whole wheat bread, tub margarine, low-fat cottage cheese and apple for lunch; and lean hamburger, brown rice, boiled cabbage and boiled butternut for dinner.

$\S \S$ Average price at the two stores calculated and used in meta-analysis.

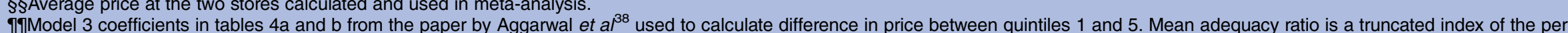
cent of daily recommended intakes for key nutrients. Computed by taking the average of nutrient adequacy ratio for 11 key nutrients: vitamins $A, C, D$, $E$ and $B_{12}$, calcium, iron, magnesium, potassium, folate and fibre. Expressed as percentage of adequacy/day

${ }_{* * \star}$ The Alternative Healthy Eating Index reflects intake of fruits, vegetables, nuts, soy, beans, white and red meats, cereal fibre, trans unsaturated fatty acids, polyunsaturated fatty acids, SFAs, alcohol and years of multivitamin use.

†††Food items identified in Western pattern were red meat, processed meats, eggs, sauces, precooked food, fast-food, caloric soft drinks, whole-fat dairy and potatoes. Food items identified in the Mediterranean pattern included olive oil, poultry, fish, low-fat dairy, legumes, fruits and vegetables.

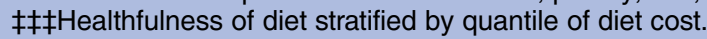

$\S \S \S N u t r i e n t$ density is defined as mean percentage daily value for vitamins $\mathrm{A}, \mathrm{C}$ and $\mathrm{E}$, calcium, magnesium, potassium and dietary fibre in $2000 \mathrm{kcal}$ of dietary energy

Пๆๆ Environmental Standards for Healthy Eating guidelines: do not serve sugar-sweetened beverages, serve water every day, serve a fruit and/or vegetable every day, do not serve foods with trans fat and when serving grains (such as bread, crackers and cereals) serve whole grains.

****Healthy Eating Index is a measure of overall diet quality based on consumption of sodium, saturated fat, total fruit, whole fruit, total vegetables, dark green and orange vegetables, milk, total grains, whole grains, meat and beans, oils and empty calories.

t†††Mediterranean diet included eating more fruits, vegetables and pulses; choosing whole-grain products; changing dietary fat intake to products containing less saturated fat and more unsaturated fat; avoiding meat and meat products; and limiting the intake of sweets, snacks and desserts.

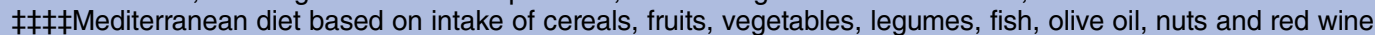

SFA, saturated fatty acid; TFA, trans-fatty acid; NHANES, National Health and Nutrition Examination Survey; USDA, United States Department of Agriculture; YMCA, Young Men's Christian Association. 

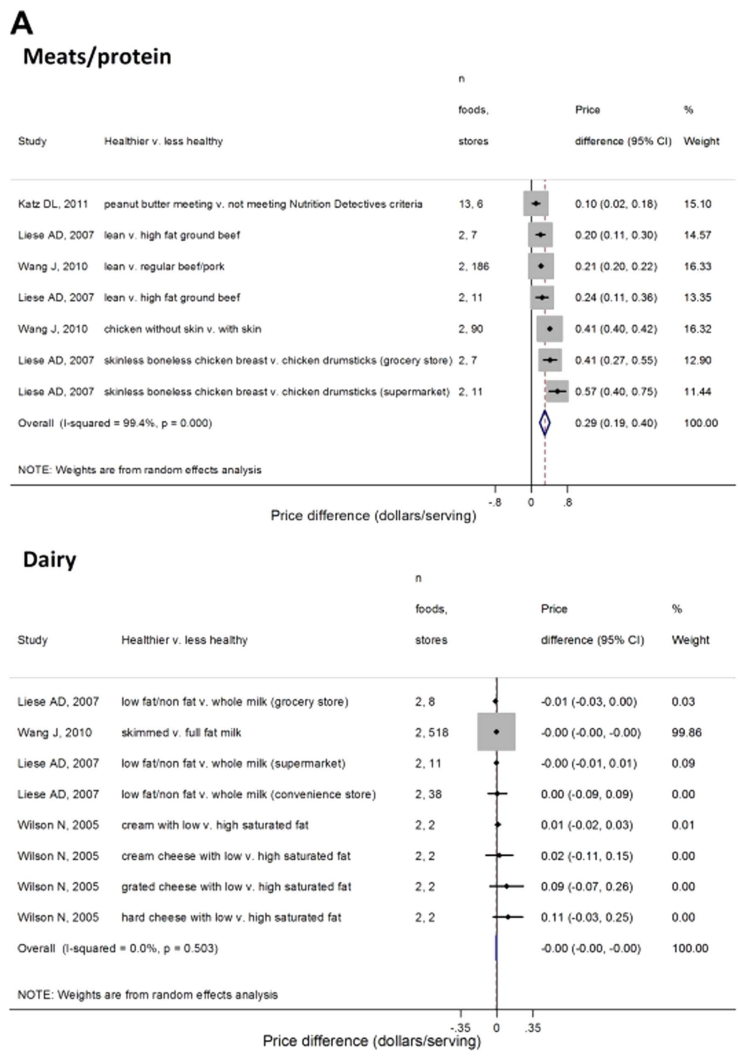

Grains

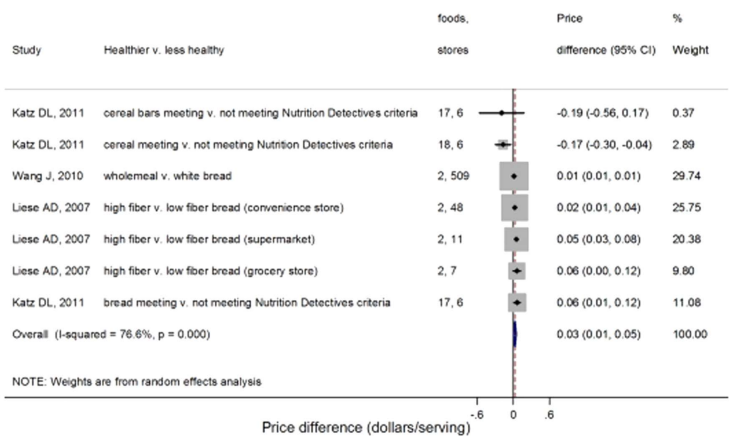

Snacks/sweets

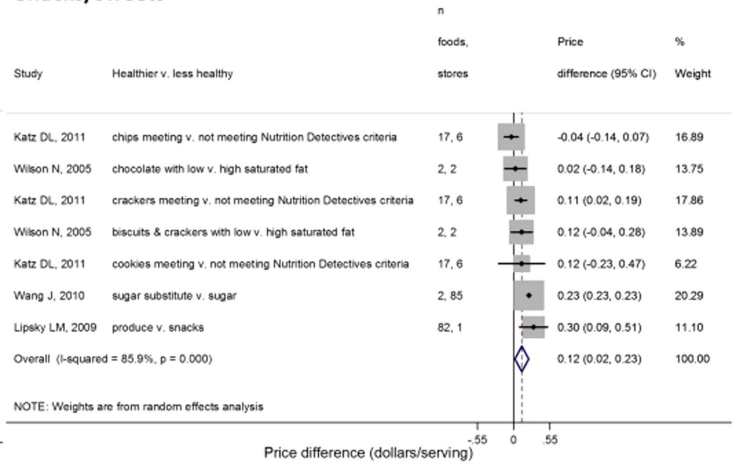

Fats/oils

Soda/juice
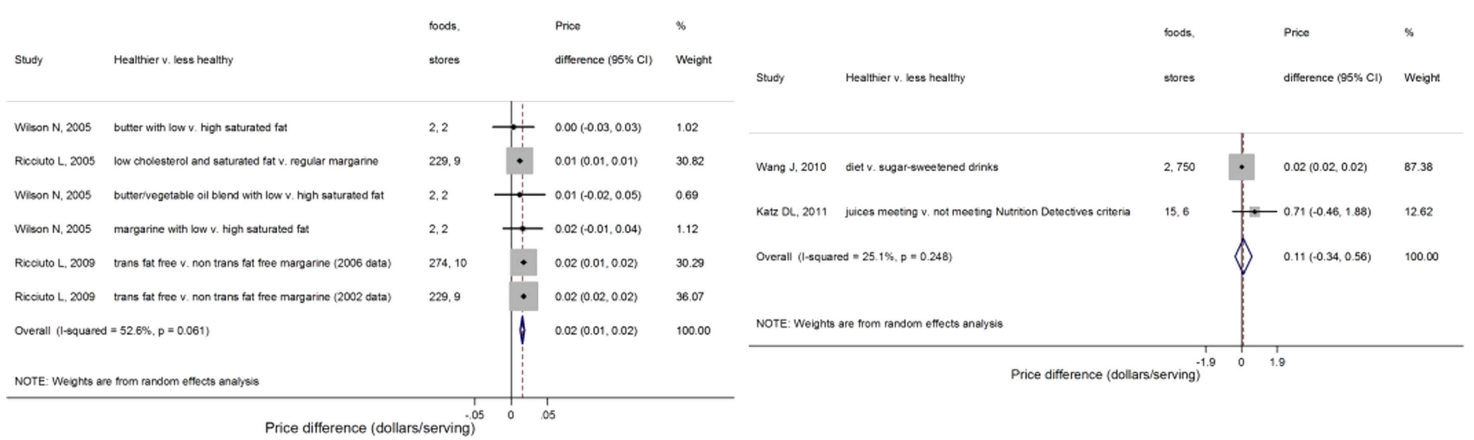

Figure 2 Price difference between healthier and less healthy foods per serving (A) and per $200 \mathrm{kcal}(\mathrm{B})$. Price difference defined as the healthier category minus the less healthy category. Standardised serving sizes were derived from the 2011 United States Department of Agriculture (USDA) MyPlate guidelines or, if not available from MyPlate, nutrition labels from a major grocery website. Calorie-adjustment of price differences based on the USDA database. Summary estimates were generated using a random effects model in which the studies were weighted according to the inverse variance of the price difference. All estimates were adjusted for inflation and purchasing power parity-standardised to the international dollar, defined as US $\$ 1$-by country to reflect the prices in 2011.

\section{Potential sources of heterogeneity}

Statistical heterogeneity as quantified by the $\mathrm{I}^{2}$ statistic was high in most analyses. Metaregression did not identify significant effect modification based on study location (USA/Canada vs other), intensity of the contrast in healthfulness or study type (market survey vs dietary survey) (data not shown). Metaregression by study type (market survey vs dietary survey) was not possible for the food group analyses due to collinearity.

\section{Publication bias}

Publication bias was assessed using the Egger test and funnel plots (supporting figure 5). ${ }^{20}$ There was no significant bias identified by the Egger test. Visual inspection of funnel plots suggested asymmetrical distributions for dairy food, food-based diet patterns and nutrient-based diet pattern comparisons, consistent with a larger number of smaller studies reporting greater price differences than the overall pooled estimate.

\section{DISCUSSION}

The findings from this systematic review and meta-analysis provide the most robust evidence until today on price differences of healthier versus less healthy foods and diet patterns. The results by food 


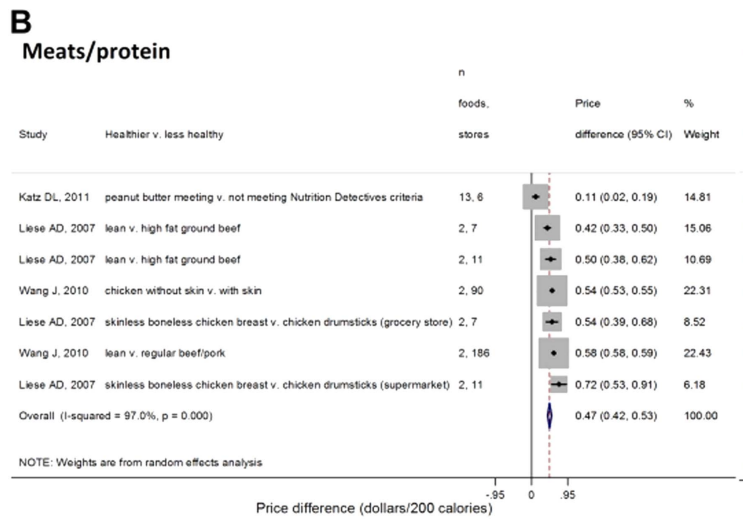

Dairy

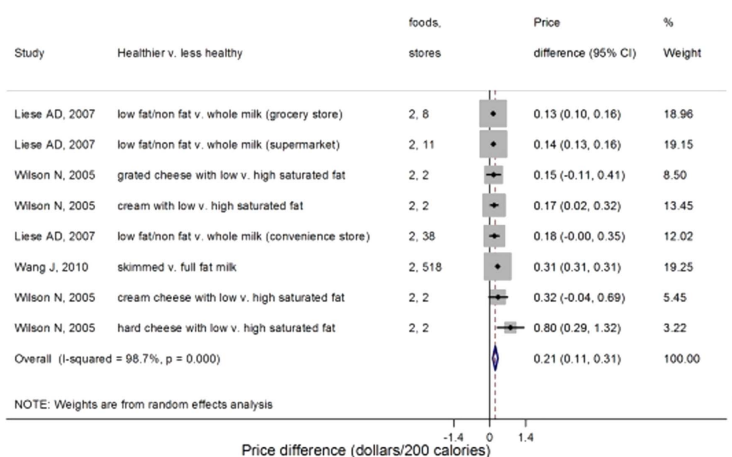

Fats/oils

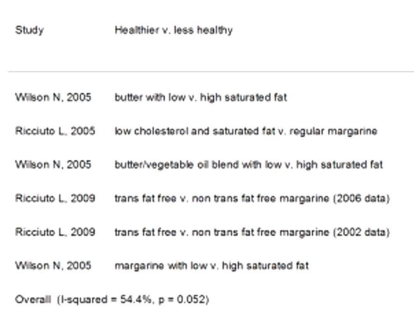

NOTE Weights are from random effects analysis
Grains

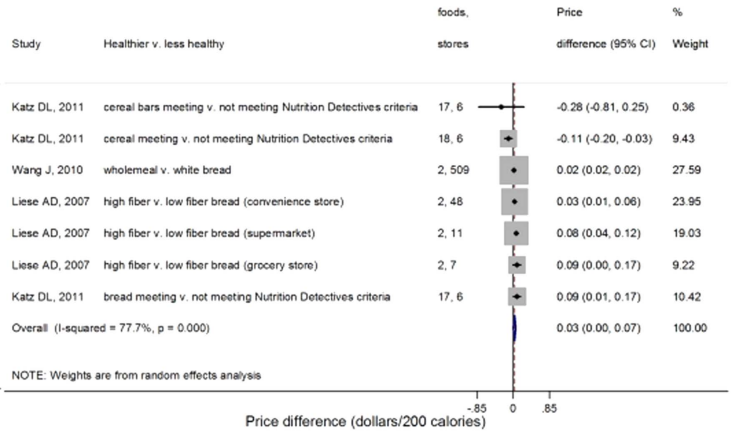

Snacks/sweets

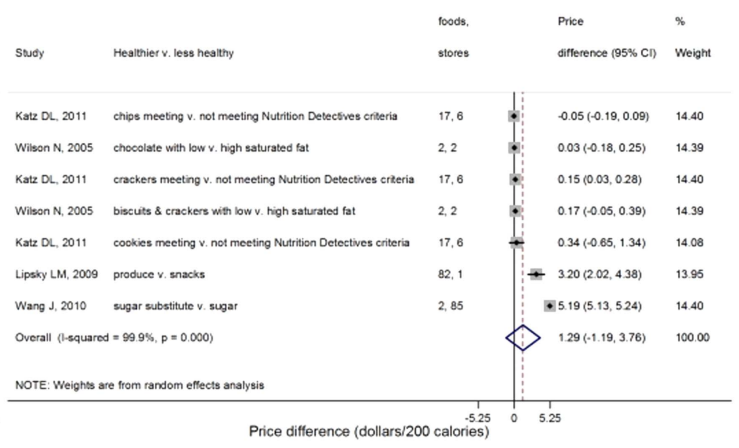

Soda/juice

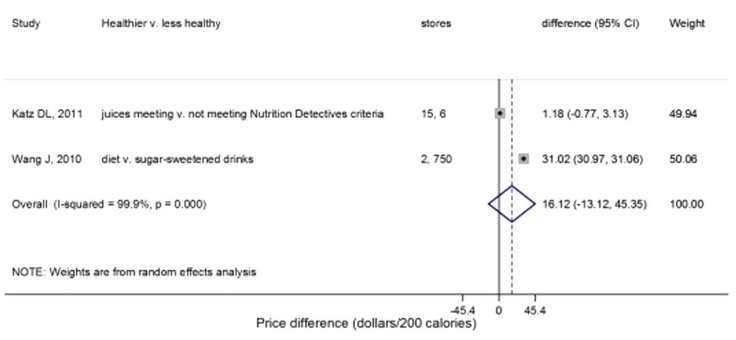

group provide insight into the relationship between healthfulness and price among similar foods. The results by diet pattern inform price differences for larger extremes of healthfulness, comparing very different foods, for example, diets rich in fruits and vegetables versus diets rich in processed foods. Although statistical heterogeneity was high, this was at least partly related to relatively small statistical uncertainty of each within-study price difference. The magnitude of clinically relevant heterogeneity was much lower, with comparatively similar price differences between studies. In addition, with a few exceptions, findings were similar across different units of price (per serving or day or calorie), intensity of contrast, study location and type of survey, thereby increasing the confidence in the validity and consistency of the findings.
Price differences of foods

Among six food groups, relatively large price differences were observed for meats/protein, as well as smaller but statistically significant differences for snacks/sweets, grains, fats/oils and dairy. According to the USDA, the farm share of proceeds of a $\$ 1$ expenditure on domestically produced food in the USA is 14.1 cents (in 2010), ${ }^{21}$ suggesting that final retail prices are determined largely by other industries and procedures in the food supply chain. Additional cost of processing and manufacturing could explain some of the identified variation in price differences; for example, lean beef and skinless chicken require more processing, perhaps accounting for their higher price. Our findings highlight the need for more research on the underlying drivers of price differences of specific items within broad food categories. 
A



Figure 3 Price difference between healthier and less healthy food-based diet patterns per day (A) and per $2000 \mathrm{kcal}$ (B). Price difference defined as the healthier category minus the less healthy category. Dollars/day was defined as dollars/three meals. One serving of any food was assumed to comprise one-fourth of a meal, except for condiments, fats and oils for which one serving was assumed to comprise one-eighth of a meal. Calorie-adjustment of price differences based on the United States Department of Agriculture (USDA) database. Information reported was not sufficient to perform calorie-adjustment for Mozaffarian et al. ${ }^{37}$ Energy density was included as a food-based pattern since this metric represents a set of foods more than it represents any single nutrient. ${ }^{19}$ For studies reporting price across quantiles of healthfulness, the most extreme quantile comparison was selected for meta-analysis. Number of participants reported for dietary surveys (studies comparing diets across samples of participants), and number of foods reported for market surveys (studies comparing samples of foods). Summary estimates were generated using a random effects model in which studies were weighted according to the inverse variance of the price difference. All estimates were adjusted for inflation and purchasing power parity—standardised to the international dollar, defined as one US \$-by country to reflect prices in 2011.

Our findings also demonstrate that, for certain metrics of healthfulness, the selected unit of comparison alters the results. In particular, metrics based largely on fat content demonstrated greater price differences per calorie than per serving. The most striking example was for dairy foods: healthier options were $\$ 0.004$ less expensive per serving but $\$ 0.21$ more expensive per $200 \mathrm{kcal}$. Whole milk contains nearly twice the calories as fat-free milk, ${ }^{17}$ so nearly double the amount of fat-free milk must be purchased to achieve equivalent calories. These findings highlight the dangers of circular reasoning (eg, selecting a metric based on fat content and then evaluating price differences per calorie) and the importance of identifying the most relevant unit of comparison for any individual or public health decision about price differences of foods. ${ }^{11}$

\section{Price differences of diet patterns}

On average, healthier food-based diet patterns were more expensive than less healthy patterns, whether based on an actual day's intake or per $2000 \mathrm{kcal}$. The price difference-about $\$ 1.50 /$ day-represents the price difference per person for consuming a much healthier versus much less healthy overall diet, for example, 
B

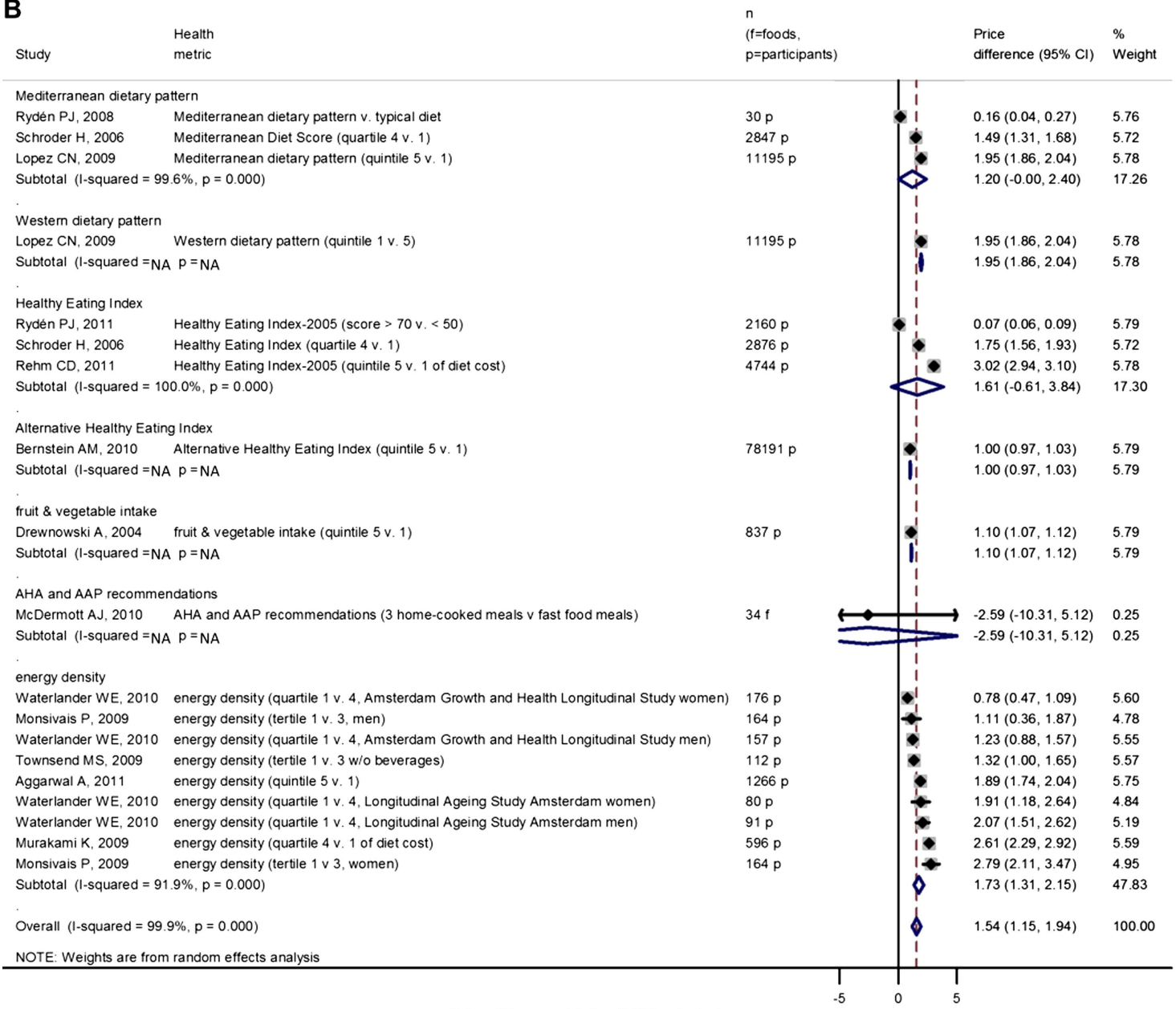

Price difference (dollars/2000 calories)

Figure 3 Continued.

comparing Mediterranean-type diets rich in fruits, vegetables, fish and nuts versus diets rich in processed foods, meats and refined grains. Thus, this price difference is for a relatively extreme contrast between the healthiest and least healthy diet pattern. Better adherence to such food-based diet patterns consistently relates to improved health and lower risk of chronic diseases. ${ }^{22} 23$

In contrast to the findings for food-based diet patterns, healthier versus less healthy nutrient-based diet patterns were not significantly different in price when based on a day's actual intake, but only cost more when standardised to $2000 \mathrm{kcal}$. These results mirror those observed when comparing individual food groups, such as dairy, based on single-nutrient metrics of healthfulness. These findings emphasise the crucial role of the unit of comparison when comparing prices by nutrientbased metrics. Healthier diets defined based on fibre or fat content will, by definition, have fewer calories, so they will naturally cost more per calorie. Yet, such diets will not necessarily cost more per serving or per meal. In the setting of a global obesity pandemic, assessing price differences per calorie may make little sense when a healthier diet also leads to reductions in total calorie consumption. Growing evidence also indicates that single or selected nutrients are less useful for distinguishing effects on major chronic diseases than types of foods and food-based diet patterns. ${ }^{13}$

\section{Heterogeneity}

In most comparisons, statistical heterogeneity as measured by $\mathrm{I}^{2}$ was high. Yet, adjustment for intensity of differences in healthfulness had little effect on pooled price differences, and meta-regression revealed no significant effect modification by intensity, study location or study type. The high $\mathrm{I}^{2}$ values may be partly explained by the relatively small statistical uncertainty for each within-study price difference. In many of the identified studies, the combination of a continuous outcome (price) and a relatively large number of samples (foods or individuals) resulted in low uncertainty of each studyspecific price difference. A lower within-study uncertainty produces higher $\mathrm{I}^{2}$ values, even when absolute magnitudes of price heterogeneity among studies may be modest from a public health or practical perspective. For example, the price differences among snacks/sweets studies fell within a relatively limited range $(-\$ 0.04$ to 
A

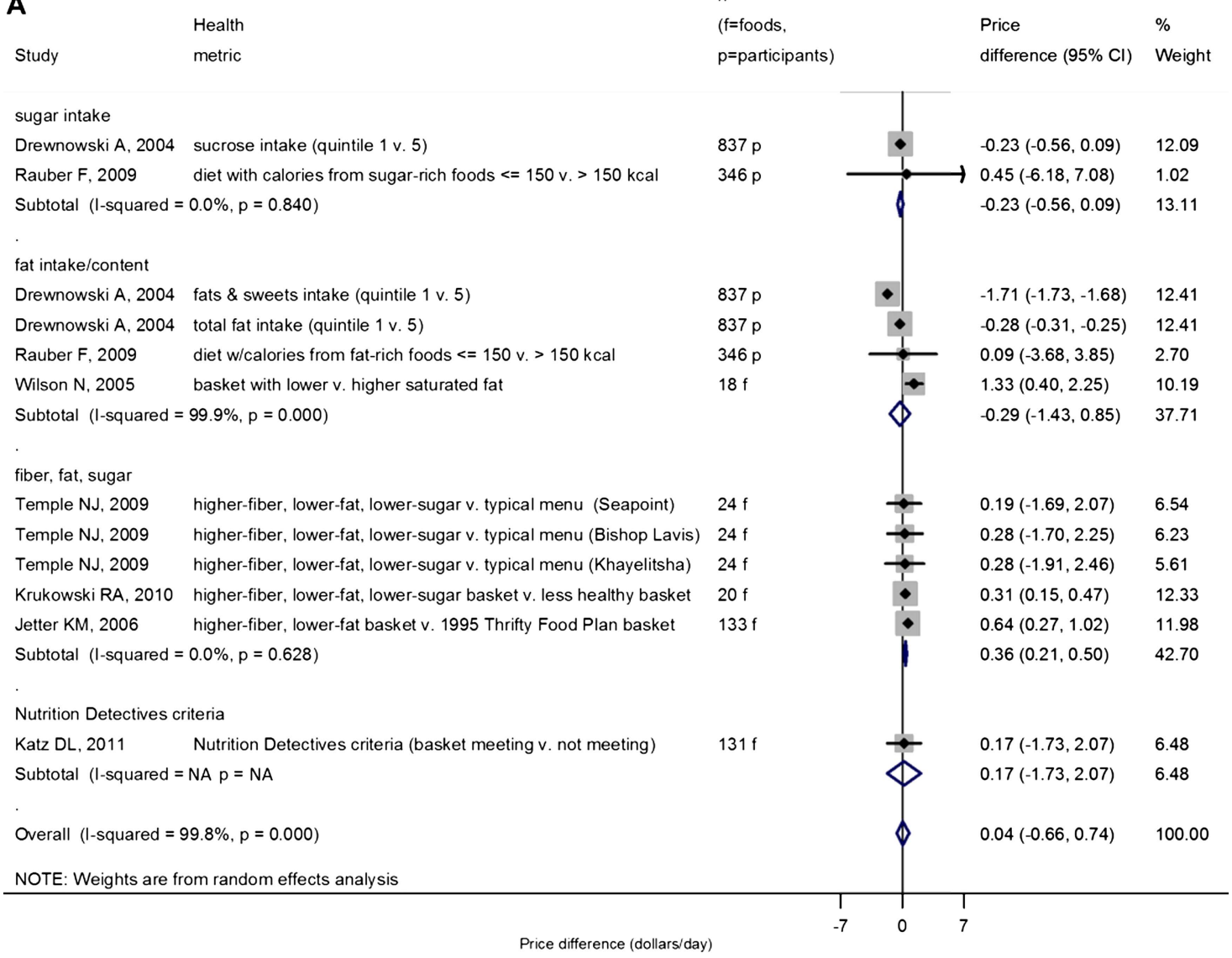

Figure 4 Price difference between healthier and less healthy nutrient-based diet patterns per day (A) and per $2000 \mathrm{kcal}(\mathrm{B})$. One outlying, implausible estimate from Aggarwal et $a^{\beta 8}$ (mean adequacy ratio) was excluded $(\$ 17.23 ; 95 \% \mathrm{Cl} \$ 14.35$ to $\$ 20.11$ ). Price difference was defined as the healthier category minus the less healthy category. Dollars/day was defined as dollars/three meals. One serving of any food was assumed to comprise one-fourth of a meal, except for condiments, fats and oils for which one serving was assumed to comprise one-eighth of a meal. Calorie-adjustment of price differences based on the United States Department of Agriculture (USDA) database. Information reported was not sufficient to perform calorie-adjustment for Temple et $a^{\beta 9}$ and Krukowski et al. ${ }^{40}$ For studies reporting price across quantiles of healthfulness, the most extreme quantile comparison was selected for meta-analysis. Number of participants reported for dietary surveys (studies comparing diets across samples of participants), and number of foods reported for market surveys (studies comparing samples of foods). Summary estimates were generated using a random effects model in which studies were weighted according to the inverse variance of the price difference. All estimates were adjusted for inflation and purchasing power parity-standardised to the international dollar, defined as US\$1 - by country to reflect prices in 2011 .

$\$ 0.30 /$ serving), with a reasonable summary estimate of $\$ 0.12$ /serving, but statistical heterogeneity was high $\left(\mathrm{I}^{2}=85.9 \%\right)$ partly due to narrow within-study CIs. Thus, the calculated heterogeneity in each summary estimate should be interpreted in light of the actual range of observed price differences across studies. Since clinically relevant heterogeneity was lower than statistical heterogeneity, the pooled results provide an insight into average price differences between healthier and less healthy foods and diet patterns.

Although similar classes of foods and diet patterns were evaluated separately, the foods or diet patterns within each category were not exactly the same. Our aim -and the relevant public health question-was not to evaluate whether one specific product costs more than another, but whether healthier foods in a broad class of foods cost more, on average, than less healthy foods in the same broad class.

\section{Strengths and limitations}

Several strengths can be highlighted. This systematic review and meta-analysis represents, to our knowledge, the most comprehensive examination of the evidence on prices of more versus less healthy foods and diet patterns. Our systematic search makes it unlikely that we missed any large reported studies. Error and bias were each minimised by independent, duplicate decisions on inclusion of studies and data extraction. Adjustment for inflation and purchasing power parity to 2011 prices accounted for the varying value of money across years and countries. The exclusion of price data prior to the year 2000 increased the generalisability of the results to 


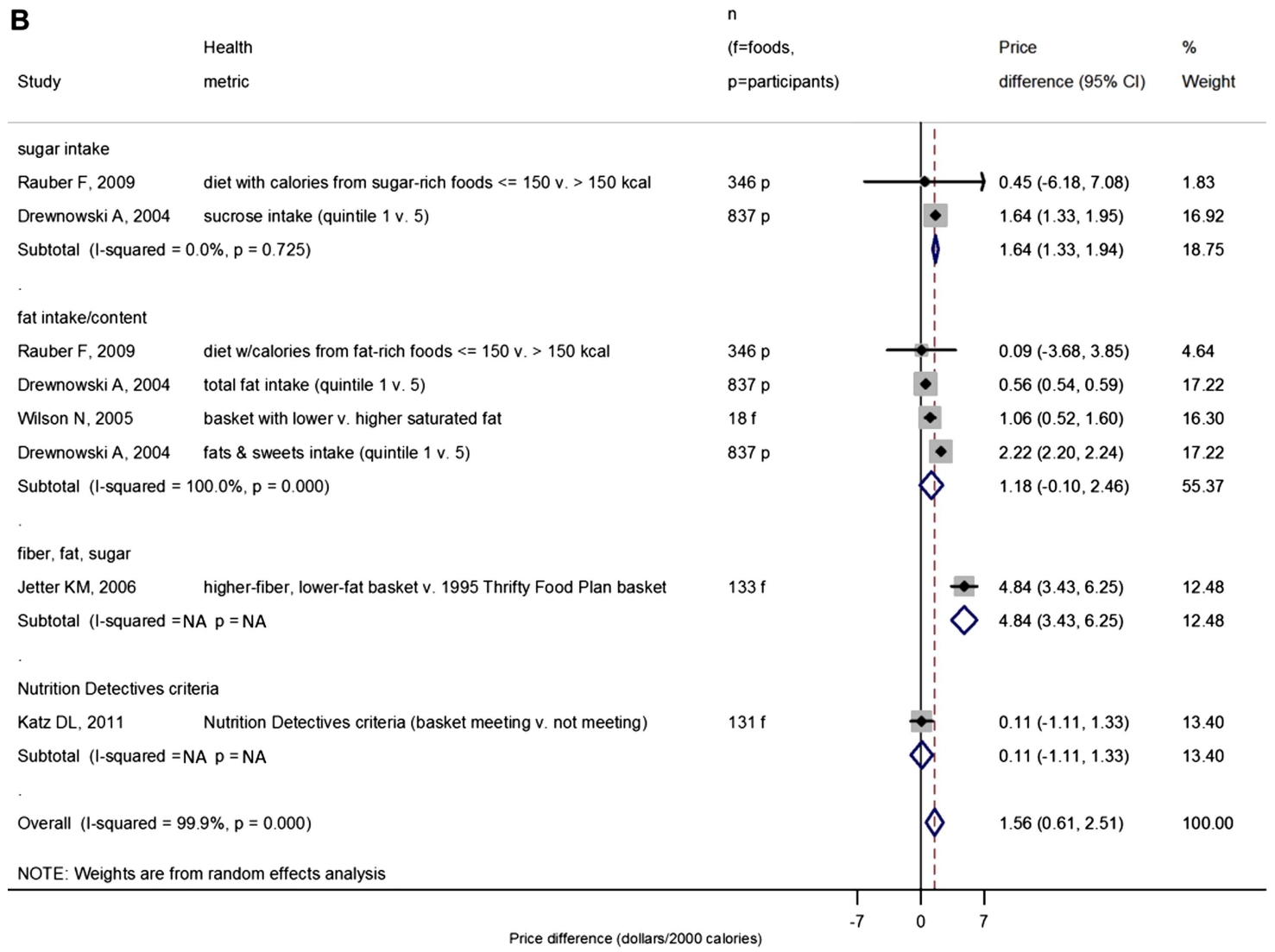

Figure 4 Continued.

contemporary diets. A key strength of our analysis was evaluation of food groups separately from diet patterns. The former provides data to inform choices when comparing otherwise relatively similar foods, whereas the latter informs price differences across very different selections of foods. Additional strengths include the standardisation of disparate metrics, foods and units; the assessment of food-based and nutrient-based diet patterns; and the evaluation of heterogeneity by food type, intensity of contrast and unit of comparison.

Potential limitations should be considered. Like all meta-analyses, our analysis was based on the available data; for certain comparisons, relatively few studies were available. For example, only one study directly compared the prices of restaurant foods with home-cooked foods; all other studies evaluated supermarket prices. Thus, our results summarise the best current data on price differences of foods and diet patterns while also highlighting the gaps in knowledge that require further investigation. Definitions of healthfulness varied across food groups and diet patterns. Yet, our findings across a variety of diet patterns and definitions of healthfulness inform how such contrasts may influence price differences. Our assessment of publication bias suggested that price differences for dairy foods and diet patterns may be partly overestimated due to selective publication of smaller studies with more extreme estimates. Statistical heterogeneity was evident in most comparisons, a significant consideration in the interpretation of the results. All meta-analyses must strike a balance between the imperative for generalisability and the need to minimise heterogeneity. Additionally, the actual range of observed price differences for many comparisons was not extreme. The rating system for intensity of contrast was subjective; yet, the ratings were assigned independently and in duplicate with good concordance and provide important sensitivity analyses on the robustness of the results. Our findings on price differences per day and per $2000 \mathrm{kcal}$ reflect an adult diet; the summary estimates should be adjusted for other caloric intakes, for example, in young children. Only English-language studies from PubMed were included, so some studies may have been missed. Given the absence of accepted criteria for judging the quality of observational studies, quality of studies was not formally assessed. Most of the comparisons were from high-income countries, highlighting the need for similar studies in low-income and middle-income nations.

\section{CONCLUSIONS}

In sum, our findings provide the most complete evidence until today on price differences of healthier foods and diet patterns, while also highlighting the importance of carefully considering the metric of healthfulness, intensity of contrast and unit of comparison. Our 
results indicate that lowering the price of healthier diet patterns—on average $\sim \$ 1.50 /$ day more expensiveshould be a goal of public health and policy efforts, and some studies suggest that this intervention can indeed reduce consumption of unhealthy foods. ${ }^{24-26}$

It remains an open question as to why healthier diets cost more. Some have argued that US agricultural subsidies for commodities (eg, corn and soy) lower the price of less healthy, more processed foods compared with unprocessed foods. ${ }^{27}$ However, careful economic analyses demonstrate that the main impact of such subsidies is a direct income transfer to farmers, with little influence on retail prices; and that tariffs and other protectionist policies are actually raising the prices of many commodities such as sugar. ${ }^{28-30}$ Conversely, many decades of policies focused on producing inexpensive, high volume commodities have led to a complex network of farming, storage, transportation, processing, manufacturing and marketing capabilities that favour sales of highly processed food products for maximal industry profit. ${ }^{31}$ Based on these experiences, efforts to create an infrastructure and commercial framework that facilitates production, transportation and marketing of healthier foods could increase the availability and reduce the prices of more healthful products. ${ }^{31}$ Taxation of less healthy foods and subsidies for healthier foods would also be an evidence-based intervention to balance price differences. ${ }^{31}$

Other potential barriers to a healthier diet exist, such as availability and cultural acceptability. However, our findings suggest that for socioeconomically disadvantaged populations, the relatively higher cost of healthy foods may be an impediment to eating better. On the other hand, Americans at all income levels allocate too little of their food budgets towards healthy foods. ${ }^{32} \mathrm{~A}$ daily price difference of $\sim \$ 1.50$ translates to $\sim \$ 550$ higher annual food costs per person. For many lowincome families, this additional cost represents a genuine barrier to healthier eating. Yet, this daily price difference is trivial in comparison with the lifetime personal and societal financial burdens of diet-related chronic diseases. ${ }^{33} 34$ For example, suboptimal diet quality was recently estimated to account for $14 \%$ of all disability-adjusted life years in 2010 in the $\mathrm{USA}^{35}$; if translated to a proportion of national health expenditures in $2012,{ }^{36}$ this corresponds to diet-related healthcare costs of $\$ 393$ billion/year or more than $\$ 1200 /$ year for every American. Our findings highlight the nuanced challenges and the opportunities for reducing financial barriers to healthy eating.

\author{
Author affiliations \\ ${ }^{1}$ The Warren Alpert Medical School of Brown University, Providence, Rhode \\ Island, USA \\ ${ }^{2}$ Department of Epidemiology, Harvard School of Public Health, Boston, \\ Massachusetts, USA \\ ${ }^{3}$ Department of Nutrition, Harvard School of Public Health, Boston, \\ Massachusetts, USA \\ ${ }^{4}$ Division of Cardiovascular Medicine, Brigham and Women's Hospital and \\ Harvard Medical School, Boston, Massachusetts, USA
}

Contributors MR and DM conceived the study design and aims and drafted the manuscript and they are the guarantors. MR, AA, and GS performed the systematic review and data extraction. MR performed the analysis. MR, AA, GS and DM interpreted the results. AA and GS contributed to manuscript revisions.

Funding Funding support was provided by a Genes and Environment Initiative (GENI) grant from the Harvard School of Public Health; by a National Heart, Lung, and Blood institute Cardiovascular Epidemiology Training Grant in Behavior, the Environment, and Global Health (T32 HL098048); and by a National Institute of Diabetes and Digestive and Kidney Diseases Training Grant in Academic Nutrition (T32 DK007703).

Competing interests None.

Provenance and peer review Not commissioned; externally peer reviewed.

Data sharing statement Technical appendix available on request from corresponding author.

Open Access This is an Open Access article distributed in accordance with the Creative Commons Attribution Non Commercial (CC BY-NC 3.0) license, which permits others to distribute, remix, adapt, build upon this work noncommercially, and license their derivative works on different terms, provided the original work is properly cited and the use is non-commercial. See: http:// creativecommons.org/licenses/by-nc/3.0/

\section{REFERENCES}

1. Banks J, Marmot M, Oldfield Z, et al. Disease and disadvantage in the United States and in England. JAMA 2006;295:2037-45.

2. Kant AK, Graubard BI. Secular trends in the association of socio-economic position with self-reported dietary attributes and biomarkers in the US population: National Health and Nutrition Examination Survey (NHANES) 1971-1975 to NHANES 1999-2002. Public Health Nutr 2007;10:158-67.

3. Mackenbach JP, Stirbu I, Roskam AJ, et al. Socioeconomic inequalities in health in 22 European countries. $N$ Engl J Med 2008;358:2468-81.

4. Darmon N, Drewnowski A. Does social class predict diet quality? $A m$ J Clin Nutr 2008;87:1107-17.

5. Bittman M. Is junk food really cheaper? The New York Times 24 September 2011.

6. Bernstein AM, Bloom DE, Rosner BA, et al. Relation of food cost to healthfulness of diet among US women. Am J Clin Nutr 2010;92:1197-203.

7. Jetter KM, Cassady DL. The availability and cost of healthier food alternatives. Am J Prev Med 2006;30:38-44.

8. McDermott AJ, Stephens MB. Cost of eating: whole foods versus convenience foods in a low-income model. Fam Med 2010;42:280-4

9. Rehm CD, Monsivais $P$, Drewnowski $A$. The quality and monetary value of diets consumed by adults in the United States. Am J Clin Nutr 2011;94:1333-9.

10. Ryden PJ, Hagfors L. Diet cost, diet quality and socio-economic position: how are they related and what contributes to differences in diet costs? Public Health Nutr 2011;14:1680-92.

11. Carlson, Andrea, and Elizabeth Frazão. Are Healthy Foods Really More Expensive? It depends on How You Measure the Price, EIB96, U.S. Department of Agriculture, Economic Research Service, May 2012.

12. Stroup DF, Berlin JA, Morton SC, et al. Meta-analysis of observational studies in epidemiology: a proposal for reporting. Meta-analysis Of Observational Studies in Epidemiology (MOOSE) group. JAMA 2000;283:2008-12.

13. Mozaffarian D, Ludwig DS. Dietary guidelines in the 21 st century-a time for food. JAMA 2010;304:681-2.

14. Rosner B. Fundamentals of biostatistics. 7th edn. Boston, MA: Brooks/Cole, Cengage Learning, 2011.

15. USDA. ChooseMyPlate.gov.

16. Peapod.

17. USDA. Food-a-Pedia

18. Azevedo JP. 'wbopendata: Stata module to access World Bank databases.' Statistical Software Components S457234: Boston College Department of Economics, 2011. http://ideas.repec.org/c/ boc/bocode/s457234.html (accessed 5 Sep 2013).

19. Drewnowski A, Darmon N, Briend A. Replacing fats and sweets with vegetables and fruits-a question of cost. Am J Public Health 2004;94:1555-9. 
20. Egger M, Davey Smith G, Schneider M, et al. Bias in meta-analysis detected by a simple, graphical test. BMJ 1997;315:629-34.

21. USDA Economic Research Service. Food Dollar Series. http://www. ers.usda.gov/publications/err-economic-research-report/err114. aspx\#.UpN7MsQWnkc (accessed 5 July 2012).

22. Mozaffarian D, Appel LJ, Van Horn L. Components of a cardioprotective diet: new insights. Circulation 2011;123:2870-91.

23. Estruch R, Ros E, Salas-Salvado J, et al. Primary prevention of cardiovascular disease with a Mediterranean diet. $N$ Engl J Med 2013;368:1279-90.

24. Andreyeva T, Long MW, Brownell KD. The impact of food prices on consumption: a systematic review of research on the price elasticity of demand for food. Am J Public Health 2010;100:216-22.

25. Powell LM, Chriqui JF, Khan T, et al. Assessing the potential effectiveness of food and beverage taxes and subsidies for improving public health: a systematic review of prices, demand and body weight outcomes. Obes Rev 2013;14:110-28.

26. Eyles $\mathrm{H}, \mathrm{Ni}$ Mhurchu $\mathrm{C}, \mathrm{Nghiem} \mathrm{N}$, et al. Food pricing strategies population diets, and non-communicable disease: a systematic review of simulation studies. PLoS Med 2012;9:e1001353.

27. For a Healthier Country, Overhaul Farm Subsidies. Scientific American 19 April 2012. accessed 5 July 2012. <http://www. scientificamerican.com/article.cfm?id=fresh-fruit-hold-the-insulin>.

28. Rickard BJ, Okrent AM, Alston JM. How have agricultural policies influenced caloric consumption in the United States? Health Econ 2013;22:316-39.

29. Beghin JC, Jensen HH. Farm policies and added sugars in US diets Center for Agricultural and Rural Development, lowa State University.

30. Harvie A, Wise TA. Sweetening the Pot: Implicit Subsidies to Corn Sweeteners and the U.S. Obesity Epidemic. GDAE Policy Brief 0901, Medford, Mass.: Global Development and Environment Institute, Tufts University, February 2009. http://www.ase.tu s.edu/gdae/Pubs/ rp/PB09-01SweeteningPotFeb09.pdf

31. Mozaffarian D, Afshin A, Benowitz NL, et al. Population approaches to improve diet, physical activity, and smoking habits: a scientific statement from the American Heart Association. Circulation 2012;126:1514-63.

32. Volpe R, Okrent A. Assessing the Healthfulness of Consumers' Grocery Purchases: U.S. Department of Agriculture, Economic Research Service, 2012

33. American Diabetes Association. Economic costs of diabetes in the U.S. in 2007. Diabetes Care 2008;31:596-615.

34. Dall TM, Zhang Y, Chen YJ, et al. The economic burden of diabetes. Health Aff (Millwood) 2010;29:297-303.

35. Collaborators USBoD. The state of US health, 1990-2010: burden of diseases, injuries, and risk factors. JAMA 2013;310:591-608.

36. National Health Expenditure Projections 2012-2022. The Office of the Actuary in the Centers for Medicare \& Medicaid Services. http://www.cms.gov/Research-Statistics-Data-and-Systems/ Statistics-Trends-and-Reports/NationalHealthExpendData/ Downloads/Proj2012.pdf (accessed 15 Oct 2013).

37. Mozaffarian RS, Andry A, Lee RM, et al. Price and healthfulness of snacks in 32 YMCA after-school programs in 4 US metropolitan areas, 2006-2008. Prev Chronic Dis 2012;9:E38.

38. Aggarwal A, Monsivais $\mathrm{P}$, Cook AJ, et al. Does diet cost mediate the relation between socioeconomic position and diet quality? Eur J Clin Nutr 2011;65:1059-66.
39. Temple NJ, Steyn NP. Food prices and energy density as barriers to healthy food patterns in Cape Town, South Africa. J Hunger Environ Nutr 2009;4:201-13.

40. Krukowski RA, West DS, Harvey-Berino J, et al. Neighborhood impact on healthy food availability and pricing in food stores. J Community Health 2010;35:315-20.

41. Cassady D, Jetter KM, Culp J. Is price a barrier to eating more fruits and vegetables for low-income families? J Am Diet Assoc 2007;107:1909-15.

42. Katz DL, Doughty K, Njike V, et al. A cost comparison of more and less nutritious food choices in US supermarkets. Public Health Nutr 2011;14:1693-9.

43. Liese AD, Weis KE, Pluto D, et al. Food store types, availability, and cost of foods in a rural environment. J Am Diet Assoc 2007;107:1916-23.

44. Lipsky LM. Are energy-dense foods really cheaper? Reexamining the relation between food price and energy density. Am J Clin Nutr 2009:90:1397-401.

45. Ricciuto L, Ip H, Tarasuk V. The relationship between price, amounts of saturated and trans fats, and nutrient content claims on margarines and oils. Can J Diet Pract Res 2005;66:252-5.

46. Ricciuto L, Lin K, Tarasuk V. A comparison of the fat composition and prices of margarines between 2002 and 2006, when new Canadian labelling regulations came into effect. Public Health Nutr 2009;12:1270-5.

47. Wang J, Williams $\mathrm{M}$, Rush $\mathrm{E}$, et al. Mapping the availability and accessibility of healthy food in rural and urban New Zealand-Te Wai o Rona: Diabetes Prevention Strategy. Public Health Nutr 2010;13:1049-55

48. Wilson $\mathrm{N}$, Mansoor O. Food pricing favours saturated fat consumption: supermarket data. N Z Med J 2005;118:U1338.

49. Lopez CN, Martinez-Gonzalez MA, Sanchez-Villegas A, et al. Costs of Mediterranean and western dietary patterns in a Spanish cohort and their relationship with prospective weight change. $J$ Epidemio Community Health 2009;63:920-7.

50. Monsivais P, Drewnowski A. Lower-energy-density diets are associated with higher monetary costs per kilocalorie and are consumed by women of higher socioeconomic status. J Am Diet Assoc 2009;109:814-22.

51. Monsivais $P$, Aggarwal A, Drewnowski A. Are socio-economic disparities in diet quality explained by diet cost? J Epidemiol Community Health 2012;66:530-5.

52. Murakami K, Miyake Y, Sasaki S, et al. Monetary diet cost is associated with not only favorable but also unfavorable aspects of diet in pregnant Japanese women: The Osaka Maternal and Child Health Study. Environ Health Insights 2009;3:27-35.

53. Rauber F, Vitolo MR. Nutritional quality and food expenditure in preschool children. J Pediatr (Rio J) 2009;85:536-40.

54. Ryden P, Sydner YM, Hagfors L. Counting the cost of healthy eating: a Swedish comparison of Mediterranean-style and ordinary diets. Int J Consum Stud 2008;32:138-46.

55. Schroder H, Marrugat J, Covas MI. High monetary costs of dietary patterns associated with lower body mass index: a population-based study. Int J Obes (Lond) 2006;30:1574-9.

56. Townsend MS, Aaron GJ, Monsivais P, et al. Less-energy-dense diets of low-income women in California are associated with higher energy-adjusted diet costs. Am J Clin Nutr 2009;89:1220-6.

57. Waterlander WE, de Haas WE, van Amstel I, et al. Energy density, energy costs and income-how are they related?. Public Health Nutr 2010;13:1599-608. 